\title{
As trajetórias do planejamento governamental no Brasil: meio século de experiências na administração pública
}

\section{Introdução}

A proposta de construção deste artigo surge, inicialmente, da constatação de que, analisando-se a literatura especializada acerca do tema do planejamento governamental, ao longo de vários anos, essa atividade experimenta uma evolução considerável. Originariamente era privilégio da chamada tecnocracia brasileira; em seguida, evolui do chamado planejamento tradicional e governamental para uma concepção de planejamento estratégico, para atingir, do ponto de vista da sociedade, a sua forma mais democrática e transparente com o planejamento, participativo, o qual, em alguns momentos, também aparece com a roupagem de orçamento participativo. Em um segundo momento, a motivação origina-se, também, do fato de que a atividade de planejamento alçada historicamente ao status de agenda governamental, começa, na década de 1980, a passar por uma crise intensa em termos de credibilidade social e de legitimidade, ao mesmo tempo em que ocorrem grandes mudanças no cenário mundial e nacional, com os movimentos de globalização econômica, o acirramento da crise financeira do Estado e do modelo burocrático de intervenção do setor público, entre outras, que afetam profundamente a sociedade.

Durante muitas décadas, na Administração Pública Federal, o planejamento foi instrumento de intervenção e controle social e também, em alguns períodos, como ocorreu na década de 1950, no governo de Juscelino Kubitscheck, com o Programa de Metas, o principal agente do desenvolvimento socioeconômico no país. Desse modo, é importante recuperar e analisar, a partir de metodologia de path dependency, as perspectivas históricas das experiências de planejamento do país, identificando, na medida do possível, resultados positivos e outros menos exitosos.

\section{Antônio \\ Ricardo de \\ Souza é \\ doutorando em Administração pela Universi- dade Federal da Bahia. \\ Contato: \\ ricjanesalvador@ terra.com.br}



trajetória do planejamento brasileiro

As raízes do planejamento governamental no Brasil datam do século XIX, sobretudo a partir de 1890, conforme Maciel (1989). Nesse período, o governo da chamada República Velha ou República Agrária institucionalizou um plano geral, conhecido como Plano de Viação, que deu os primeiros passos rumo à sistematização da coordenação das contas públicas no país. Posteriormente, já no fim do século XIX, em função dos desequilíbrios das contas públicas, o governo criou o Plano de Recuperação Econômico-Financeira, coordenado pelo então Ministro da Fazenda Joaquim Murtinho. Entretanto, somente a partir do advento do Estado Novo, nos anos 30, é que o Brasil ingressa sistematicamente na adoção e concepção de planejamento governamental (MACIEL, 1989). Num primeiro momento, essa prática de planejamento inicia-se por meio de pequenas comissões e coordenações ad hoc que, vinham para o país auxiliar governos e burocracias públicas na sistematização de planos, programas e projetos de ação, o que, posteriormente, transformou-se em atividade da Administração Pública Federal, responsável pela condução dos negócios públicos, pelos investimentos, pelo crescimento econômico e pelo desenvolvimento social.

Para fins de análises das experiências de planejamento no Brasil, uma agenda de debates poderia ser apresentada a partir de dois grandes divisores de águas em relação à política, à economia e à definição do marco legal-institucional do país: o primeiro é o Estado Novo de 1930, momento em que se inicia a construção de um Estado capitalista de caráter nacional-desenvolvimentista, planejador e intervencionista; e o segundo é o Regime Militar de 1964, em que essas relações construídas no Estado capitalista aprofundam-se e internacionalizam-se, guiadas por racionalidade técnica e de eficiência econômica, articuladas com ideologia de segurança nacional. Assim, esses dois períodos ou marcos políticos de análises serão os grandes eixos norteadores da identificação sucinta das experiências brasileiras de planejamento econômico no país.

É a partir dos anos 30 que, no Brasil, inicia-se a construção de cultura e prática de planejamento governamental, assentado nas principais bases da incipiente industrialização brasileira, na intervenção do Estado, na criação de empresas públicas e estatais, na valorização do capital nacional e na política nacionalista de defesa dos interesses das elites industrializantes (IANNI, 1986). As iniciativas que vigoraram nas décadas de 1930 e 1940 culminaram com forte intervenção do Estado na sociedade, por meio do planejamento governamental.

É importante enfatizar que, nesse primeiro momento de adoção de planejamento pela Administração Pública Brasileira, coube ao Estado o 
papel de principal indutor e condutor da atividade de planejamento econômico, assim como à sua burocracia estatal o papel de implementação das ações governamentais, que ainda prevalecem até os dias atuais.

Durante os primeiros anos do Estado Novo de 1930, as elites governantes (políticas, agrárias e industrializantes) empenharam-se em viabilizar a tão propalada industrialização brasileira, via processo de substituição de importações. É a partir de discurso nacionalista, estatizante e intervencionista, principalmente, que o Estado brasileiro fomenta iniciativas, como a valorização do capital e da empresa nacional, para viabilizar a política de industrialização, tendo como base algumas ações que, até aquele momento, não se constituíam, ainda, em planejamento governamental. Tais iniciativas tinham como objetivos construir um Estado capitalista brasileiro dotado de economia forte, com base nacional, e, dessa forma, viabilizar as suas relações de produção com maior ênfase na presença do setor estatal no processo de industrialização. Um dos grandes desafios dos anos 30 foi, a partir das empresas públicas estatais, as elites criarem um modelo de desenvolvimento planejado, com ênfase somente no capital nacional e na valorização do mercado interno. Ou seja, as elites do Estado Novo queriam implementar no país um processo de industrialização com bases predominantemente nacionalistas, sem interferências externas que pudessem ferir os grandes objetivos nacionais.

Dentro desse contexto, alguns autores, como Ianni (1987), Láfer (1987), Kon (1999), afirmam que é, a partir das décadas de 1930 e 1940, que o Brasil cria iniciativas importantes que originaram a atividade de planejamento governamental. Tais iniciativas são apresentadas nas seguintes propostas: 1) Relatório Simonsen (1944-1945); 2) Missão Cooke (19421943); 3) Missão Abbink (1948); 4) Comissão Mista Brasil - EUA (19511953); 5) Plano Salte (1948), que contribuíram para criar e articular cultura e prática de planejamento que viessem atender às principais demandas sociais. Entretanto, mesmo antes dessas importantes iniciativas governamentais, houve ainda esforços para construir matriz decisória global que pudesse criar instrumentos de política econômica para os setores públicos e privados no país, de acordo com Souza (1984).

Esses esforços estão esposados nas caracterizações do Plano de Obras e Equipamentos, que teve como base o Plano Especial de Obras Públicas e Preparo da Defesa Nacional, decorrentes das necessidades do período da Segunda Grande Guerra, no período de 1939-1945; a Coordenação da Mobilização Econômica de 1942, em que o governo coordenava assuntos econômicos, financeiros, tecnológicos do país em estado de guerra; o Plano Salte (1949-1953), que priorizava os setores da Saúde, da Alimentação, do Transporte e da Energia, implementado pelo Departamento Administrativo do Serviço Público (DASP); o Plano de Reaparelhamento Econômico ou Plano Láfer, anunciado em 1951 e coordenado 
pelo Ministro da Fazenda Horácio Láfer, que objetivava investimentos nas indústrias de base, energia, frigoríficos, entre outras (SouzA, 1984; IANNI, 1986). Todos esses esforços contribuíram não somente para a construção de cultura e prática de planejamento no país, como colaboraram na determinação de colocar mais racionalidade nas ações e no processo decisório das políticas governamentais.

Para Souza (1984), o Plano de Metas do Governo Juscelino Kubitschek, para o período de 1956-1961, não era um plano, e, sim, um programa, por não terem sido concebidos em sua formulação programas e projetos de ação governamental. Assim, esse plano caracterizou-se por vir acompanhado de articulação entre o capital privado nacional, o capital estrangeiro e o Estado, no processo de industrialização, que foi fortemente acentuado no governo JK (Kon, 1999).

No período seguinte, de 1963 a 1965, durante o governo Jânio Quadros e João Goulart, foi desenvolvido o Plano Trienal, que objetiva a recuperação do ritmo de crescimento econômico no período do governo JK (MACEDo, 1987). Esse plano foi formulado e coordenado pelo economista brasileiro Celso Furtado, que nem sequer conseguiu articular ações no governo que pudessem tirá-lo do papel e levá-lo para a sociedade.

Assim, após a renúncia de Jânio e a deposição do Presidente Jango pelo golpe militar de 1964, as perspectivas econômicas e sociais de crescimento são postergadas para os governos militares que se instalam no período pós-64 no país.

Um dos primeiros atos do novo regime militar foi a retomada do crescimento da economia, comprometida pelos governos anteriores de Jânio e Jango, por meio do Plano de Ação Econômica do Governo (PAEG) para o período de 1964-1966.

Posteriormente, já em processo de retomada do crescimento econômico, a partir de algumas reformas importantes, como a institucional e a do sistema tributário brasileiro, o regime militar lança mão do Programa Estratégico de Desenvolvimento (PED), para o período de 1968-1970, tendo como objetivos a valorização da empresa privada e a aceleração do desenvolvimento econômico, com a estabilização de preços e o controle inflacionário.

Já, na década de 1970, o Brasil inicia período grandioso de crescimento e desenvolvimento econômico, capitaneado pela intervenção do Estado, por meio do planejamento econômico, tendo como base os altos níveis de crescimento do Produto Interno Bruto nacional. Assim, é a partir do I Plano Nacional de Desenvolvimento Econômico, o I PND, para o período de 1972-1974, que o país alavancou o seu padrão de crescimento econômico com base em investimentos em setores dinâmicos, como a construção e ampliação da infra-estrutura do país, assim como a disseminação de política e ideologia de desenvolvimento nacional pautada na 
forte presença do Estado e de suas empresas públicas, estatais e sociedade de economia mista (MARTINS, 1985).

Dessa forma, sob os auspícios da máquina estatal e da ação eficiente do planejamento governamental na Administração Pública Federal, o Brasil, assim como todos os países capitalistas, foi abalado pela primeira crise do petróleo, que culminou com o aumento dos preços internacionais, em fins dos anos de 1973, provocando crise internacional de reajustes nas contas nacionais (Kon, 1999). Então, o regime militar brasileiro reage com a implementação do II Plano Nacional de Desenvolvimento, o II PND, para o período de 1975-1979, que previa um programa de investimentos condizentes com as altas taxas de crescimento dessa década. Esse período foi extremamente turbulento, tendo em vista que ocorreu, ainda em 1979, a segunda crise do petróleo, que forçou, novamente, as economias a se reajustarem e a viabilizarem alternativas de políticas econômicas que pudessem superar as dificuldades causadas pelos aumentos do preço do barril de petróleo, que ficaram $37,9 \%$ acima do preço do ano anterior.

Nos anos 1980-1985, em relação à queda do ritmo de investimentos e à diminuição de demanda, restringindo o crescimento da produção, o regime militar tenta alavancar a economia com a implementação do III Plano Nacional de Desenvolvimento, o III PND, que concebeu diversas alterações em relação ao I e II PNDs, e, na prática, significou uma busca pelo equilíbrio do setor público/contas públicas, tentando controlar o déficit fiscal e a inflação. Não por acaso, a partir da década de 1980, o controle inflacionário passa a ser estratégico para o governo militar para assegurar não só a retomada do crescimento econômico, mas, também, o controle sobre a inflação, de forma a não inviabilizar no país os interesses das grandes empresas privadas e do grande capital nacional e internacional, que sempre estiveram vinculados ao Estado brasileiro.

Assim, o Brasil entra na década de 1980 - considerada por membros da classe política, analistas e economistas como a "década perdida" -, tendo como centro de sua agenda governamental o controle da inflação e a retomada do crescimento econômico. É bom frisar que, não por acaso, já existia, desde os anos 30, preocupação com a questão inflacionária, mas é a partir dos anos 80 que a inflação passa a ser o grande desafio estratégico dos sucessivos governos.

\section{Planejamento governamental e suas principais características nas experiências brasileiras}

As principais experiências de planejamento aqui apresentadas têm como base duas iniciativas importantes para o país, porém não estratégicas. A primeira é o Plano de Obras e Equipamentos, que teve como seu 
antecessor o Plano de Obras Públicas e Preparo da Defesa Nacional no Brasil, que tinha a finalidade de preparar o país para os infortúnios da Segunda Guerra Mundial. Esses dois planos foram elaborados pelo mesmo governo de Getúlio Vargas, no período do Estado Novo. Sua ênfase recaía na construção de obras de infra-estrutura e na criação de indústrias de base, que seriam as grandes alavancas do processo de industrialização. Nesse período, esses planos não concebiam as condições financeiras em que se dava a concretização das intenções do governo. O que se verifica é que, do ponto de vista administrativo, esses planos legitimavam a posição de poder do ministro da Fazenda, na medida em que coube ao Ministério da Fazenda a condução das políticas e articulações para a formulação, implementação e coordenação do planejamento, no período de 1939-1945. Esses planos sofreram alterações em 1945 e praticamente foram extintos em 1946 (SouzA, 1984). A queda de Vargas, a Constituição de 1946 e os fatos que findaram a Segunda Guerra Mundial forçaram o Brasil a retomar posição de destaque como democracia da América Latina. Por isso adotou iniciativas e princípios do liberalismo econômico, retomou o crescimento econômico, realizou reformas na Administração Pública Federal e, apontando na direção da renovação de sua frota mercante e de sua infraestrutura, reequipou portos (SoUZA, 1984; IANNI, 1986; LÁFER, 1987).

Assim, a partir desse quadro, o país acena com o Plano Salte (Saúde, Alimentação, Transporte e Energia), coordenado pelo Departamento Administrativo do Serviço Público (DASP), no governo do General Eurico Gaspar Dutra, para o período de 1946-1950, implementa política fortemente antiintervencionista, herdada da era ditatorial de Vargas, prioriza, além deste plano, a política cambial, a salarial e, sobretudo, a Missão Abbink em 1948, que era uma comissão ad hoc do governo americano encarregada de assessorar e diagnosticar as questões nacionais mais importantes - os chamados "pontos de estrangulamento" (IANNI, 1986) da economia e da sociedade brasileira - e propor políticas e estratégias governamentais voltadas para a superação das dificuldades do país à época. O governo Dutra apresentou alguns avanços sociais, como a democratização do país, e também alguns retrocessos políticos, como a cassação do Partido Comunista, mas caracterizou-se por uma política externa de proximidade com os Estados Unidos da América a partir da doutrina e da ideologia liberal, tanto do Estado como do aparato público-estatal, permitindo a presença incessante dos interesses internacionais no país. O que os especialistas apontam é que o Plano Salte acabou sendo um apanágio de retóricas e intenções governamentais sem nenhuma articulação de política econômica, apresentando graves equívocos de financiamento e omissão de aspectos administrativos, que culminaram com a total desarticulação entre o orçamento e o próprio plano. Para Souza (1984), não é por acaso que, à época, especialistas afirmavam que o plano era 
totalmente inexeqüível em relação à proposta governamental. Apesar das

incongruências, dos equívocos e das inconsistências apresentadas no Plano Salte, o governo Dutra inicia a sua implementação a partir de 1949, já no final de seu período governamental. Em suma, poderíamos afirmar que essa experiência de planejamento, em plena democracia liberal no Brasil, foi pautada pela falta de aportes financeiros, pela não-formulação de projetos e programas governamentais, pela desarticulação financeira e orçamentária, pela ineficiência da administração pública governamental em relação à articulação e coordenação de políticas e pela sua discutível viabilidade técnica. Portanto, o Plano Salte tornou-se antiexemplo de planejamento governamental no Brasil (SouZA, 1984).

Para além das incompreensões apresentadas pelo Plano Salte, o Brasil inicia a próxima década, de 1950, convivendo com o retorno da mais importante liderança política e um dos grandes "arquitetos" da construção do Estado brasileiro, o Presidente Getúlio Vargas, para seu segundo governo, de 1951 a 1954.

Nesse segundo governo, o Presidente Getúlio Vargas encontrou um país já democratizado, um Estado já privatizado e permeado pelos interesses dos grandes capitalistas e pelas elites nacionais e internacionais, além de uma política econômica liberalizante (IANNI, 1986). Além disso, já existia, de forma consolidada, uma burguesia industrial que demandava do Estado políticas e articulações que viessem ao encontro de suas grandes aspirações de produção e consumo. Nesse período, a tônica do governo Vargas, do ponto de vista político-ideológico, foi combater o que ele chamava de entreguismo da nação aos capitalistas nacionais e internacionais, realizando algumas iniciativas de planejamento, como foi o Plano Nacional de Reaparelhamento Econômico, ou Plano Láfer ${ }^{1}$, anunciado em 1951, juntamente com a criação de um Fundo de Reaparelhamento Econômico para financiar iniciativas público-privadas, e, principalmente, a criação de agência de fomento, como o Banco Nacional do Desenvolvimento Econômico (BNDE), em 1952, além da Petrobras, BNB, BASA, Bandesul, Eletrobrás, encarregados de financiar principalmente o crescimento nos setores de infra-estrutura e obras públicas, viabilizando, assim, o desenvolvimento econômico do país (SouzA, 1984; IANNI, 1986).

Para além dessas realizações, o governo Vargas não conseguiu concretizar outras iniciativas na administração federal, mesmo que tímidas, pois tinha de superar as dificuldades e os obstáculos criados pelos grandes interesses nacionais e internacionais das elites capitalistas, que mantinham, a todo custo, o controle do poder político por meio do Congresso Nacional e do aparelho do Estado. Assim, ficou evidenciado que tais interesses eram incompatíveis com os objetivos nacionais à época. Além do mais, havia, em desenvolvimento no país, uma sociedade mais articulada politicamente, convivendo com os partidos políticos de oposição 
e de esquerda de forma livre e democrática, em ambiente em que as regras do livre mercado dirigiam os destinos de toda a economia nacional.

Assim, a partir desse quadro político-econômico, o Presidente Getúlio Vargas, diante de sua incapacidade e fragilidade política de enfrentar essas dificuldades em pleno regime democrático, provocou grave crise institucional com seu suicídio em 25 de agosto de 1954, mergulhando o país em grandes dificuldades e dilemas institucionais. Portanto, o que há, nesse período, sobre planejamento governamental é que, apesar das intenções de Vargas de realizar políticas nacionalistas que defendessem os interesses nacionais, como retratou bem a criação da Petrobras, o governo não conseguiu retomar as condições político-econômicas que pudessem tirar o Brasil da situação de transição, ou seja, de país com características predominantemente agrárias para outro, moderno, industrial e inserido na economia capitalista mundial.

Assim, verifica-se que, no período que antecede o governo de Juscelino Kubitschek (JK), o Brasil já tinha incorporado uma racionalidade técnica, incipiente - resultado das experiências anteriores sobre a adoção do planejamento governamental -, que combinava três pontos importantes em relação ao sistema econômico brasileiro e à dinâmica capitalista mundial: 1) o poder público no país já tinha incorporado as experiências de planejamento, manipulando os instrumentos de política econômica; 2) desde 1948, a Comissão Econômica para a América Latina (Cepal) vinha desenvolvendo debates e propostas de desenvolvimento conforme a estratégia de substituição de importações, programação econômica nos níveis setorial, regional e global, que praticamente dominou a agenda governamental nesse período; e 3) os EUA já tinham iniciado suas experiências no governo e em setores empresariais, pelas quais já era possível identificar a participação do Estado nas decisões e propostas de realizações sócioeconômicas para a população e, com isso, alavancar o processo de industrialização. Em suma, pode-se afirmar que havia reordenamento das relações econômicas entre o Estado e as forças produtivas do país (DRAIBE, 1985; IANNI, 1986; BIELSCHOWSKY, 1988).

Além desses precedentes do período JK no Brasil, enfatiza-se que esse governo herdou grave crise de instabilidade política, derivada do suicídio do Presidente Getúlio Vargas em 1954 e do movimento militar de novembro de 1955, movimento que tinha como objetivo garantir a instalação do governo recém-eleito em outubro do mesmo ano. Assim, poderíamos afirmar que o período JK herdou grandes turbulências políticas, mas foi capaz de iniciá-lo com uma das mais exitosas experiências de planejamento governamental: o Programa de Metas, que vigorou no Brasil a partir de um discurso político, ideológico, retratado no slogan: "Brasil, 50 anos em cinco". 
Esse programa adotou uma estratégia de governo muito interessante e diferente do que vinha sendo adotado pelos governos anteriores, que foi a transformação qualitativa do Estado em termos de política econômica, com a expansão do Estado e do capitalismo brasileiro, de forma dependente e associada aos grandes interesses econômicos e empresariais nacionais e internacionais (SouZA, 1984). Tal estratégia dependentista de JK foi marcada por quatro grandes realizações para o Brasil: 1) a implementação do Programa de Metas, que será analisada em seguida; 2) a criação da Superintendência do Desenvolvimento do Nordeste (Sudene), em1959, que tinha como objetivo principal o combate às secas e às desigualdades regionais; 3) a Operação Pan-Americana (OPA), que visava à aproximação dos países da América Latina entre si e com os Estados Unidos; e 4) a construção de Brasília, que transferiu a capital do país do Rio de Janeiro para a região do Planalto Central, em 1960 (IANNI, 1986).

O que interessa, então, nesse período do governo JK é analisar o Programa de Metas, que deu início à consolidação de modelo de crescimento e desenvolvimento econômico, articulados com o processo de industrialização, capitaneado pelo Estado, o que propiciou, desta forma, grandes transformações nas estruturas produtiva, pública e estatal no Brasil (IANNI, 1986; DRAIBE, 1985).

O Programa de Metas tinha sido estruturado para atacar pontos de estrangulamento da economia brasileira, viabilizando investimentos em infraestrutura, sob a responsabilidade do Estado, pois nessa época esse setor não constituía setor atrativo para investimentos do setor privado, e expandindo o setor de indústria de base - automotivo, indústria pesada e de material elétrico - para dar condições de criação, instalação e consolidação do parque industrial nacional (IANNI, 1986, LÁFER, 1987).

De acordo com Láfer (1987), o Programa de Metas atingia os seguintes setores: 1) energia, que abrangia $43,4 \%$ do investimento inicialmente planejado e compreendia as seguintes metas: setor elétrico elevação da capacidade instalada em até 9.000 .000 kW em 1965; energia nuclear - formação de pessoal técnico especializado para a execução do programa nacional de energia nuclear, para fabricar combustível nuclear, planejar usinas termelétricas, entre outras; carvão mineral - elevação da produção mineral para até 3.000.000 de toneladas; petróleo - criação de condições para o refino de até 308.000 b/d; 2) transporte, que abrangia $29,6 \%$ dos investimentos e estava dividido nos seguintes segmentos: ferrovias, que necessitavam de reaparelhamento, construções novas e modernização urgentemente; rodovias, que necessitavam ser construídas e pavimentadas para criar condições concretas para o escoamento da produção e a integração do país; melhoria dos serviços de dragagens e portuários; investimentos na marinha mercante, nos transportes aeroviários para que pudessem dar maior consistência ao crescimento econômico no 
período; 3) alimentação, que contemplou a agricultura, à exceção do trigo, criando condições de fortalecimento da infra-estrutura agrícola a partir das seguintes estratégias: aumento do número de construções de armazéns e silos, armazéns frigoríficos e matadouros industriais, mecanização e uso de fertilizantes. Esse setor foi privilegiado com um crescimento, entre 1955-1960, de 7,2\% aa, contrastando com a ínfima taxa de 3,3\% no início da década de 1950; 4) indústria de base, setor estratégico para o sucesso do Programa de Metas, que aumentou vigorosamente, no período, a produção industrial em mais de 96\% em relação ao período de 1952-1955, que crescera apenas $42 \%$. Essa produção industrial diversificou os bens de tal forma que o setor dividia-se em: siderurgia, que ultrapassou a meta em 1960, com uma produção do parque siderúrgico em 2.485.000 toneladas; alumínio, cuja produção foi de 16.573 toneladas; metais não ferrosos, com a expansão, principalmente, das indústrias de chumbo, estanho, níquel e cobre; produção de cimento, álcalis, celulose e papel, borracha e exportação de minérios de ferro, que atingiu aumento de até $94 \%$ em relação ao Plano de Metas; o setor da indústria automobilística praticamente consolidou o seu apogeu com a meta atingida de 92,3\% em 1960, acompanhado pelas indústrias de construção, metal-mecânica e de material elétrico, que tiveram significativos aumentos de produção para o período; 5) educação, setor ainda secundarizado e não contemplado ainda nas políticas e no planejamento governamental. No Programa de Metas, a educação, timidamente, apresentava como objetivo viabilizar a qualificação técnica do pessoal do setor produtivo por meio dos chamados cursos técnicos especializados (LÁFER, 1987).

Além dessas questões, o Programa de Metas, apesar de ter tido muito sucesso econômico à época, apresentava algumas debilidades/dificuldades administrativas, como: ausência de integração das áreas executiva do plano com a financeira; manipulação de alguns instrumentos de política econômica sem lógica racional que estruturasse as atividades necessárias para o atendimento das pressões sociais e as exigências técnicas do programa; e a necessidade de reforma administrativa coerente, com o objetivo de ajustar a Administração Pública Federal, o Estado e os objetivos do Programa de Metas (SouzA, 1984).

Finalizando, poder-se-ia, então, afirmar que o Programa de Metas traduziu, por meio da atividade de planejamento governamental, os interesses das elites nacionais e internacionais capitalistas de viabilizar no Brasil a consolidação de um modelo de crescimento econômico capitalista dinâmico, a partir da intervenção do Estado como o grande mentor do desenvolvimento econômico e social (SouZA, 1984; LÁFER, 1987).

Antes da análise do Plano Trienal, é importante enfatizar, mais uma vez, outra crise político-institucional que ocorreu no país, com o interregno do governo de Jânio Quadros (1961-1964), que tomou posse em 31 de 
janeiro de 1961. Após oito meses de governo, em 25 de agosto desse ano,

alegando que "forças ocultas o impediam de governar o país", ele renuncia ao cargo de Presidente da República do Brasil, mergulhando o país em mais uma crise de instabilidade política, econômica, social e institucional.

Não vem ao caso tratar dessa questão neste artigo, entretanto é importante frisar que essa posição tomada pelo Presidente Jânio Quadros, além de surpreender o povo brasileiro, que tinha depositado nele todas as esperanças de retomada do crescimento, de combate ao desemprego e à corrupção no país, vem corroborar as análises e opiniões a respeito de sua personalidade dúbia, equivocada e, às vezes, inexplicável, na medida em que ele demonstrava, em seus discursos, uma mistura de discurso oficial inerente ao poder público com propostas de caráter moralista e laico.

Além da crise instalada pela renúncia de Jânio, o governo de Jango herdou, também, contexto turbulento em função dos limites impostos pelo mau desempenho econômico, pelos altos níveis de desemprego e inflação, pela total desorganização do setor público e, sobretudo, pela falta de apoio político das elites, dos militares e de parte da classe média brasileira. Também, aliado a esse confronto político de crise institucional, o governo de Jango viu-se pressionado por interesses internacionais, em particular dos americanos, que pressionavam o governo em busca de política mais liberal e menos restritiva em termos de concessão às grandes empresas capitalistas.

Nesse quadro crítico, o governo de Jango implementa o Plano Trienal para o período de 1963-1965, elaborado por técnicos brasileiros em fins de 1962, sob a coordenação do renomado economista brasileiro Celso Furtado, com o objetivo de retomar o crescimento econômico, reduzir o processo inflacionário e criar condições concretas para a distribuição de renda e a intensificação da ação governamental na área educacional (SouZA, 1984; Kon, 1999; IANNI, 1986; MACEDO, 1987).

O Plano Trienal, desde o primeiro momento, demonstrou, conforme Souza (1984), grandes níveis de incongruência. Tais níveis estão expressos no fato de que, nesse governo, criou-se um superministério, ou um ministro extraordinário para a atividade de planejamento, rompendo, dessa forma, com as concepções de planejamento como atividade acessória ou, segundo as agências financeiras, como algo predominantemente voltado para uma lógica racional. Outra incongruência do Plano Trienal era o seu autoritarismo na formulação, ou seja, foi planejado de cima para baixo, sem participação social e de outros níveis governamentais e administrativos da administração pública do país. Ainda nesse quadro de incongruências, o plano era predominantemente tecnocrático, porque dominado por técnicos (economistas) e burocratas, os principais responsáveis pela formulação das políticas públicas. Entretanto, houve um ponto positivo no Plano Trienal: 
a competência com que se deu a integração entre a política econômica e as proposições das ações governamentais do plano (SouZA, 1984).

Diante de tal quadro de crises político-socioeconômicas desse período em que se gerou o Plano Trienal do governo de Jango, o resultado, sem dúvida nenhuma, mostra total fracasso gerencial, político e administrativo, levando alguns analistas a afirmar que o plano nem saiu do papel. Em 1963, criou uma Coordenação de Planejamento Nacional, para tentar recompor o plano a partir de outras bases; no entanto, ele morrera atacado pelos altos níveis inflacionários, pelo baixo nível de crescimento e pela falta de investimentos para a retomada do crescimento econômico do país (SouzA, 1984; MACEDO, 1987).

Após a desilusão deixada pelo fracasso do Plano Trienal e pelos malogrados governos de Jânio e, sobretudo, após a deposição do Presidente Jango por um golpe militar, em março de 1964, o Brasil ingressa na chamada era dos governos militares.

Não é propósito, neste artigo, analisar o golpe militar de 31 de março de 1964 no país, no entanto é a partir desse período que o Brasil adota o planejamento governamental como instrumento de intervenção e controle social, além dos objetivos de desenvolvimento.

O ciclo do governo militar no Brasil tem início com a ascensão do Presidente Marechal Humberto de Alencar Castello Branco, que formulou e implementou o mais intervencionista planejamento governamental, depois dos anos 30, no Brasil: o Plano de Ação Econômica do Governo (PAEG) para o período 1964-1966.

De acordo com Martone (1987), o PAEG fazia parte das chamadas reformas institucionais relevantes desse período e apontava para os seguintes principais objetivos: a) combater o processo inflacionário; b) acelerar o ritmo de crescimento econômico; c) atenuar os desníveis de desenvolvimentos setoriais e regionais; d) assegurar uma política de investimentos; e) aumentar as oportunidades de emprego.

Um dos elementos políticos que mais caracterizavam o PAEG como instrumento de intervenção e controle social era o total controle sobre as variáveis "políticas" para executar uma política planificada no país (IANNI, 1986).

Para Souza (1984), além dessa característica, o PAEG ainda possuía as seguintes qualidades e pontos positivos em termos de planejamento governamental: 1) significava uma primeira tentativa de integrar a política econômica de forma coerente; 2) havia sincronia entre as pastas do Planejamento e da Fazenda; 3) havia em curso ampla reforma da Administração Pública Federal, para articular de forma mais eficiente os aspectos macro e a realização dos objetivos do Governo Federal. Entretanto, o que mais se destacava no PAEG era um conjunto de diretrizes de política econômica integradas, voltadas para a estabilização da economia, 
tendo como objetivo central a excessiva preocupação em combater a inflação, de forma coordenada e como prioridade da agenda governamental (SouzA, 1984; MARTONE, 1987).

O PAEG também capitaneou, além do combate inflacionário, duas grandes reformas no setor das finanças públicas: a do Sistema MonetárioCreditício, em 1964, e a Reforma Financeira, em 1965, estabelecendo as principais bases de modernização financeira do país, criando novos instrumentos de crédito, como: a) a Coordenação Nacional de Crédito Rural (CNCR); b) o Fundo de Democratização do Capital das Empresas (Fundece); c) o Fundo de Financiamento para a Aquisição de Máquinas e Equipamentos Industriais (Finame); d) o Fundo de Financiamento de Estudos e Projetos e Programas (Finep); e) o Banco Nacional de Habitação (BNH) (SouZA, 1984; IANNI, 1986; Kon, 1999). Tais reformas propiciaram o desenvolvimento do sistema financeiro brasileiro.

Tal como ocorreu com a grande maioria dos planos governamentais do país, os retrocessos e os avanços nessa atividade de planejamento deixaram marcas profundas na definição cultural e prática de planejamento governamental no Brasil.

Assim, a exemplo disso, pode-se afirmar que existiram três importantes dimensões contempladas no PAEG, que, de acordo com Souza (1984), significaram grandes avanços em relação às experiências anteriores: 1) a identificação do uso de diagnósticos, que serviram de base para formulação do plano nas áreas econômica e social; 2) o correto uso da política econômica; e 3) a reforma e modernização da Administração Pública Federal, com o objetivo de instrumentalizá-la em relação às necessidades de implementação da política econômica. Tais dimensões tiveram papel importante na formulação e implementação do plano, servindo de lição e exemplo para os futuros planejamentos públicos do governo.

Em relação aos retrocessos do PAEG, Souza (1984) aponta os seguintes elementos: a) inconsistência nos dados devido ao sistema estatístico ser débil, defasado e deixar grandes dúvidas a respeito das informações que precisariam ser coletadas na formulação do diagnóstico; b) a reforma administrativa pretendida, por mais que avançasse, não atingiu os objetivos de descentralização e eficiência das ações administrativas do governo; c) as recorrentes mudanças institucionais e trocas de técnicos para a formulação e gestão dos planos contribuíram para a sua baixa eficiência, pois os técnicos da área de planejamento do Governo Federal eram recrutados de fora do setor público, com salários e garantias trabalhistas diferenciadas, gerando instabilidade e mudança na condução dos negócios públicos, incapacitando o governo de criar cultura e competência na Administração Pública Federal.

Em suma, em que pesem as dificuldades político-institucionais enfrentadas pelo PAEG, no período de 1964-1966, pode-se afirmar que, 
pela primeira vez, o governo adota a atividade de planejamento de forma sistematizada, articulada e integrada com a política econômica, priorizando, dessa forma, a agenda pública governamental.

A partir de 1967, foi publicado o Plano Estratégico de Desenvolvimento (PED) para o período de 1968-1970, durante o governo do Marechal Costa e Silva, que estava apoiado, num primeiro momento, no combate ao processo inflacionário e na retomada acelerada do desenvolvimento, e, num segundo momento, apontava na direção do fortalecimento da empresa privada, na estabilização gradativa dos preços, na consolidação de infraestrutura pelo governo e no fortalecimento e ampliação do mercado interno (Alves; SAYAd, 1987; Kon, 1999).

Alguns analistas apontam que o PED foi diagnosticado a partir da crise da economia no período de 1962, no momento em que a economia brasileira enfrentava uma de suas grandes crises, com o esgotamento do processo de substituição de importações e a estagnação econômica. Assim, num contexto de crise e estagnação econômica, conforme Alves e Sayad (1987), o PED foi concebido para alterar os padrões econômicos de desenvolvimento à época, corrigindo algumas distorções herdadas de anos anteriores, que ainda permeavam a economia brasileira. Tais distorções, como a crescente inflação e as dificuldades econômico-financeiras do processo de industrialização brasileira, paralisaram o desenvolvimento a partir de 1962 e o crescimento vertiginoso do setor público na economia, provocando elevado custo de oportunidade. Em suma, tais distorções, acabaram conduzindo a economia do país a uma retração nas taxas de crescimento do produto nacional bruto.

Finalmente, o PED demonstrou que o Brasil já possuía experiência acumulada em planejamento governamental, com base já definida e estruturada na Administração Pública Federal, que consolidava, nesse primeiro momento, um modelo de planejamento que se caracterizava pela sua consistência analítica e definição de metas de médio prazo mais precisas, voltadas para a retomada do desenvolvimento econômico do país. Assim, o PED representa certo nível de avanço na prática e na cultura do planejamento governamental no país.

A partir da década de 1970, o regime militar adota estratégia de crescimento e desenvolvimento econômico caracterizada pela formulação e implementação dos Planos Nacionais de Desenvolvimento (PNDs), que vigoraram no país até meados da década de 1980.

Esse período, conhecido como a Era dos PNDs, por causa do I, II e III PNDs durante os governos militares, estendeu-se até o governo Sarney, da Nova República, em 1985. Assim, o planejamento, durante os governos militares, tornou-se paradigmático para o Brasil, na medida em que prepara o país para o crescimento e o desenvolvimento econômico amparados em ideologia de segurança nacional - o seu salto para a modernidade. 
Conforme Kon (1999) e Gremaud e Pires (1999), o I PND, formulado para o período de 1972-1974, vem acompanhado pelo fenômeno econômico conhecido como "milagre" econômico, que tinha as seguintes premissas: a) as reformas econômico-financeiras introduzidas no período 1964-1967 aumentaram a capacidade de investimento do Estado brasileiro; b) o quadro externo de crescimento econômico, propiciou grande liquidez no mercado financeiro mundial; e c) a existência de capacidade ociosa, como resultado da crise econômica de 1962-1966. Assim, a partir desses fatores, consolidaram-se no país, como resultado econômico, altos níveis de crescimento do PIB, o que levou o país, em 1973, a atingir metas de até $7 \%$ aa. de crescimento econômico - percentual histórico para o país. Além desse quadro econômico favorável, nesse contexto de "milagre" econômico, o país entra em processo de enrijecimento governamental, do ponto de vista político-institucional, com a promulgação do Ato Institucional nํ 5, o AI-5, como ficou conhecido, editado em novembro de 1968, que proibia todo tipo de manifestação político-social, dando amplos poderes ao Poder Executivo, configurando-se como o mais duro momento do regime militar. É a partir desse quadro de êxito econômico e dura intervenção do regime militar na sociedade que o governo lança o I PND, que continha, além das principais metas e bases para a ação do governo - que visava à definição de objetivos nacionais e o atingimento das metas estratégicas governamentais -, duas outras dimensões de política econômica: o Orçamento Plurianual de Investimentos para o período de 1971-1973 e o I Plano Nacional de Desenvolvimento Econômico e Social para o período de 1972-1974 (Gremaud; Pires, 1999).

Assim, o I PND apresenta ideologia, em sua retórica, de forma muito eficiente em termos de ganhos econômicos, numa proposta de governo que era tornar o Brasil uma das grandes potências econômicas e bélicas até fím do século XX. Esse sentimento nacional-patriótico dos militares foi muito bem esposado no documento que apresentou o I PND, a partir da seguinte afirmação: “(...) objetivava-se, no período de uma geração, transformar o Brasil em nação desenvolvida”.

As principais diretrizes governamentais dos militares norteadoras do I PND foram: a) a modernização da sociedade; b) a otimização dos recursos humanos; e c) a definição de uma política de integração nacional com o objetivo de promover o progresso e a ocupação em diversas regiões do país.

Para Gremaud e Pires (1999), o I PND tinha como linhas básicas de ação as seguintes estratégias de crescimento econômico: a) aumento do crescimento por meio da aceleração da economia, aumentando-se o PIB para $9 \%$ aa., procurando fazer o país alcançar a posição de oitava economia do mundo ocidental. Uma outra questão que envolve essa variável econômica 
é o aumento do emprego, que deveria crescer a uma taxa média de $3 \%$ entre 1970 e 1974 . Então, haveria esforço concentrado nos setores terciário, da agricultura e da construção civil, de forma a propiciar aumento do nível de emprego para combater as pressões advindas dos grandes centros populacionais. Observa-se, ainda, que a maior parte das fontes de crescimento passa a ser aqueles setores que aumentaram sua produtividade a partir dos ganhos tecnológicos. Outrossim, enfatiza-se que, no governo do General Médice, viabilizou-se, entre outras políticas, a criação de instrumentos para favorecer o setor privado da economia por meio de financiamentos do Banco Central do Brasil (Bacen), Banco Nacional de Desenvolvimento Econômico (BNDE) e Banco Nacional de Habitação (BNH); b) outra estratégia do I PND foi o papel que as empresas públicas e estatais realizaram no país, assim como as fontes de financiamentos para a modernização da Administração Pública Federal. Tudo isso trazia, como consequiência, crescimento desmesurado do aparato público-estatal, provocando brutal centralização político-institucional e econômica, assim como hipertrofia do Poder Executivo na condução dos negócios públicos. Não vem ao caso analisar, neste artigo, a expansão do Estado no Brasil nesse período, mas vale citar que Martins (1985) realizou estudo clássico sobre a expansão do Estado no Brasil pós-64, em que apontou nessa direção da hipertrofia do Poder Executivo e da expansão da materialidade do Estado por meio das empresas estatais na Administração Pública Federal do país; c) a integração nacional foi acompanhada da Política de Integração Nacional (PIN), que disseminava os resultados do progresso econômico a partir de centros de crescimento regionais e de seus efeitos multiplicadores, de acordo com as vantagens comparativas; d) a política econômica; e) a distribuição de renda também estava nessa agenda, como quesito importante na execução do I PND no Brasil.

Os resultados do Plano de Metas e Bases para a Ação de Governo, para o período 1970-1973, e do I Plano Nacional de Desenvolvimento, para o período 1972-1974, foram estrondosos, pois o país alcançou níveis de crescimento que variaram de $7 \%$ a $9 \%$, entre 1970 e1973, atingindo $10 \%$, em 1973, e, entre $8 \%$ e 10\%, em 1974, segundo o I PND, superando todas as expectativas governamentais do regime militar no país. Ainda, nessa mesma linha de argumentação, além dos resultados dessas intervenções planejadas dos governos militares, soma-se, também, o combate às disparidades setoriais entre a agricultura e a indústria, culminando com a liderança inconteste do setor industrial, que teve crescimento médio de $12 \%$, contrastando com o crescimento tímido de $4 \%$ da agricultura. Neste período, a primeira crise do petróleo acirrou o conflito distributivo, forçando o governo militar a deixar que o processo inflacionário do país se encarregasse de distribuir os custos das alterações de preços dos combustíveis e derivados do petróleo (MARTINS, 1985). Não é objetivo deste artigo analisar 
a primeira nem a segunda crise do petróleo no mundo capitalista à época, no entanto é condição sine qua non o seu entendimento, para conhecerem-se os desdobramentos dessa crise nas economias capitalistas mundiais.

Assim, além do que foi apresentado e analisado, o I PND retrata de forma inexorável a ideologia e a política de crescimento e desenvolvimento econômico com segurança nacional, o que vigorou até meados dos anos 80 no país. Seguiram-se, nessa mesma racionalidade de desenvolvimento, a formulação e a implementação do II PND no Brasil, que dava sequiência à lógica de acumulação capitalista capitaneada pelo Estado e assegurada pelos governos militares.

Como afirmado anteriormente, o contexto da crise do petróleo, forçando os reajustes das economias mundiais e impondo novas condicionantes econômicas nesses países, gerou, na concepção do II PND para o período 1975-1979, um programa de investimentos voltados à taxa média de crescimento de $10 \%$ a.a., tendo como estratégia econômica o processo de substituição de importações. Para Gremaud e Pires (1999), o II PND passa a ser, então, o planejamento mais importante nesse momento, para os governos militares, na medida em que esse plano representa uma reação à crise do petróleo e ao rompimento das regras de Bretton Woods, merecendo, dessa forma, destaque especial em termos de estratégia de desenvolvimento econômico para o Brasil.

A principal diretriz do II PND era o crescimento econômico de forma acelerado e contínuo, que tinha como retórica a afirmação do Brasil potência e a continuação da política econômica antiinflacionária por meio do gradualismo, da manutenção do equilíbrio na balança de pagamentos, entre outros. Nesse sentido, os choques do petróleo não alteraram os objetivos do plano, no entanto o Brasil teve de recorrer ao endividamento externo para reagir às novas condicionantes impostas pela nova situação mundial.

Ainda, segundo Gremaud e Pires (1999), o II PND desenhava um modelo econômico com as seguintes características: a) consolidação da economia moderna de mercado, que refletisse preocupação contínua com crescimento e competitividade; b) ênfase na sociedade, fortalecendo o setor agropecuário; e c) condições concretas para assegurar equilíbrio entre o capital nacional e o estrangeiro. As principais áreas de atuação do plano foram: 1) consolidação de economia moderna na região Centro-Sul do país, apontando, também, para desconcentração industrial mais bem distribuída regionalmente; 2 ) desenvolvimento de novas fontes de energia; 3 ) intensificação da política de integração regional; 4) combate à pobreza, atacando os principais focos no país; e 5) integração com a economia mundial.

O II PND priorizava a política industrial voltada para a consolidação de matriz industrial brasileira condizente com a dos países desenvolvidos, expandindo os setores de base, abrindo novos campos de exportação, dando novo impulso tecnológico e amenizando os níveis de 
desigualdades regionais. No setor agrícola, a direção dada pelo plano foi de modernização e expansão das fronteiras agrícolas, com a execução de política de uso da terra para fins agropecuários, a definição de política de reforma agrária e a adoção de estratégia global para o setor rural.

Além das principais características e dimensões apontadas no II PND, os resultados são significativos no que se refere à substituição de importações, ao aumento das exportações e à concretização de grande parte dos projetos de desenvolvimento.

Assim, deve-se considerar que os principais resultados alcançados entre meados das décadas de 1970 e 1980 foram, em grande parte, operados pelo II PND. A produção de aço, por exemplo, foi significativa para o país, levando-se em conta que, no período 1970-1974, o gasto com as importações de aço decuplicaram, passando de 160 milhões para 1,5 bilhão de dólares. As metas estabelecidas no II PND apontavam para a produção de aço em 22,3 milhões de toneladas até 1979. A produção no país acabou atingindo, nesse ano, 13,9 milhões de toneladas, portanto $63 \%$ do total das metas do plano. É importante observar que, mesmo que as metas alcançadas, no caso dos aços, sejam menos significativas que as pretendidas pelo II PND, os altos níveis observados em relação à importação e à exportação culminaram com a redução das necessidades de importação, de um total de 39\%, em 1974, para $3 \%$, em 1979, ampliando significativamente os excedentes exportáveis de $2 \%$ para 38\%, no período de 1974-1983 (Gremaud; Pires, 1999).

Outros resultados apontados pelo II PND envolvem, também, o setor de energia, que, em função da crise mundial do petróleo, forçou país a investir no incremento da produção nacional do petróleo e em fontes alternativas, como o Proálcool. Verificou-se que a prioridade de aumento da produção do petróleo ampliou-a bastante, passando de 27\% em 1974 para $70 \%$ em 1980. Tal aumento decorreu principalmente dos investimentos aplicados no refino e transporte do petróleo, culminando, dessa forma, em resultados significativos de produção de até $17 \%$ a.a, no período de 1979-1986. Além desse aumento na produção do petróleo, é importante também frisar que a produção de energia alternativa, como a energia elétrica ligada à cana-de-açúcar, foi muito significativa em 1974 e 1979, com aumentos anuais de $12 \%$ e $9 \%$, respectivamente. Outros resultados surpreendentes da economia brasileira durante o II PND apontam ainda na direção de outros setores que também foram muito importantes para o crescimento econômico do país, como os bens de capital e comunicações (KoN, 1999).

O III PND, para o período 1980-1985, foi formulado em conjuntura de turbulências econômicas no balanço de pagamentos, pressões sobre alta de preços, pagamento da dívida externa e níveis crescentes de desemprego. 
As principais estratégias do III PND apontavam nas seguintes direções: a) priorização do setor agrícola e de abastecimento, com vistas ao aumento da produção, estímulo às pesquisas, criação de sistemas integrado de produção e política fundiária, entre outros; b) na área industrial, propiciou a elevação da produtividade do setor, com incentivos aos principais projetos industriais de política energética e ampliação das exportações; c) na área de energia, apoio a programas de racionalização do uso da energia, prioridade à substituição do uso de derivados de petróleo, acelerando o Programa Nacional do Álcool e novos projetos de geração hidrelétrica e de aproveitamento de outras fontes de energia; e d) na área social, democratização da cultura e educação no país, criação de condições de valorização do trabalho, habitação e maior participação social nas políticas públicas e sociais. Tais estratégias, fortemente abaladas pela crise externa da economia já no início da década de 1980, não conseguiram, de forma geral, retomar o crescimento econômico e, principalmente, combater os altos níveis inflacionários no país. A recessão econômica de 1981-1983 e os altos níveis de inflação, que, a partir de 1984 até 1986 , atingiram o patamar de $220 \%$ a.a., comprometeram o poder de compra dos salários, aumentando a exclusão social e provocando tensões no campo e nas cidades (GREMAud; PIRES, 1999). Então, a partir desse quadro de crises e dificuldades financeiras, aliadas ao atraso tecnológico e à ausência de política industrial efetiva, o país tenta retomar os rumos da economia com a adoção de novo plano econômico.

\section{A decadência do planejamento como instrumento do desenvolvimento e a ascensão da agenda neoliberal no Brasil}

A década de 1990 foi a da Reforma do Estado. É a partir desse momento, na sociedade contemporânea, que o Estado passa a ser questionado, criticado e apontado como o grande vilão da crise financeira, que vinha sendo diagnosticada desde fins da década de 1970 e início dos anos 80. Não foi por acaso que o Brasil se inseriu nesse conjunto de países que sofreu os impactos tanto do processo de globalização da economia como da crise do Estado fiscal, aqui entendido como exaustão financeira do Estado, que impossibilita financiar políticas públicas e promover o desenvolvimento social. É a partir dessas premissas e em articulação com a adoção de agenda liberal que o Brasil abandona as políticas de médio e longo prazo, optando por uma política de manutenção de curto prazo, que dá conta das expectativas financeiras mais imediatas, abandonando e/ou preterindo o planejamento que, durante muitos anos, foi o grande instrumento de crescimento econômico no país. 
Assim, a implementação da agenda neoliberal nos países da América Latina e, em especial, no Brasil passou a apontar na direção das chamadas reformas estruturais e/ou ajustes estruturais, como o redimensionamento do papel do Estado e de seu caráter de intervenção no setor público; a reforma fiscal e tributária, com objetivo de equilibrar as contas públicas; a reforma administrativa, tornando o serviço público mais eficiente; e maior eficiência das políticas públicas e sociais.

Essa agenda neoliberal, com base nas privatizações de empresas públicas, tinha como característica preparar o país para viabilizar modelo de capitalismo globalizado, centrado nos mercados e com uma estabilidade monetária condizente com os interesses dos mercados financeiros mais desenvolvidos.

Assim, não é por acaso que o país incorpora na sua política macroeconômica, centrada nos juros altos e no câmbio fixo, um dilema que inviabiliza o crescimento e a possibilidade de planejamento: a total dependência do poder público em relação ao capital financeiro especulativo para financiar suas políticas públicas. Além desses requisitos econômicos, somam-se os juros altos e os baixos níveis de investimentos na produção, comprometendo ainda mais a retomada do crescimento econômico do país. Assim, essa dinâmica econômica capitalista e globalizada, imediatista e financeiramente predatória em termos de produção, passa a ser a principal matriz orientadora e norteadora do crescimento econômico do país, que, com base nas políticas de curto prazo, dão respostas mais rápidas e eficientes na dinâmica financeira global.

O Brasil perde sua visão e perspectiva de longo prazo, reduzindo os investimentos na produção, na criação de emprego, no financiamento das políticas públicas e sociais, na alavancagem financeira das pequenas e médias empresas e, de forma geral, passa a ser dependente das políticas de curto prazo voltadas para a financeirização da riqueza, que se acumula de forma desproporcional no país. O resultado de tudo isso é o aumento do desemprego, a ausência de políticas públicas e sociais, o aumento da fome e da miséria social, que contribuem cada vez mais para o aumento dos excluídos do processo de crescimento econômico e do desenvolvimento social do país.

Por último, mas não menos importante, o que mais caracteriza a decadência do planejamento no país, a nosso juízo, é a ausência de um projeto de nação e de tomadas de decisão que valorizem a sociedade a curto, médio e longo prazos e tragam benefícios materiais e sociais compatíveis com uma sociedade desenvolvida. 


\section{Conclusões}

Diante do exposto, fica evidenciado que, de acordo com as trajetórias do planejamento governamental como instrumento do desenvolvimento econômico e social, o país sofreu, ao longo do tempo, avanços e retrocessos em relação à utilização do planejamento governamental.

Como se afirmou inicialmente, neste artigo, não se pretende dar conta das complexidades que envolvem as diversas dinâmicas do Estado, da economia e da sociedade em geral e, em particular, dos impactos dos diversos planos no desenvolvimento da sociedade brasileira. Entretanto, é necessário conhecer e compreender as trajetórias históricas dos planejamentos no Brasil, as suas características principais, seus objetivos, fracassos e sucessos, de forma a melhor entender os diversos períodos dos ciclos econômicos e desenvolvimentistas do país, que foram fundamentais na definição do atual modelo de desenvolvimento socioeconômico.

Também ficou evidenciado que, nessa perspectiva histórica apresentada, o papel do Estado na direção da economia foi fundamental e decisiva na priorização de programas, planos e políticas de desenvolvimento econômico, que, salvo melhor juízo, no conjunto das suas ações, não conseguiram superar as desigualdades sociais e de renda, que ainda prevalecem na sociedade brasileira. Tais desigualdades envolvem o aumento da pobreza e da miséria social no país, acentuado pela grande concentração de renda e falta de políticas de redistribuição de renda, políticas de emprego e ações sociais emancipatórias e de justiça social, voltadas para a melhoria da qualidade de vida da sociedade e, principalmente, para a inclusão social de grandes segmentos sociais marginalizados pelo crescimento da economia.

Além dessas questões, a opção política do país pela manutenção de políticas econômicas de corte liberal, apontando na direção da estabilidade macroeconômica, e o atendimento das metas de combate à inflação são fatores que contribuem para a diminuição dos investimentos sociais em algumas áreas, como as de educação, saúde e saneamento básico.

O quadro socioeconômico do país apresenta diagnóstico inexorável: o país não conseguiu recuperar e retomar o ritmo de crescimento econômico em 2004, na medida em que as prioridades de investimentos são canalizadas para o equilíbrio das contas públicas e a manutenção das metas antiinflacionárias. Ou seja: é impossível um país como o Brasil buscar o desenvolvimento social, na medida em que, na ausência de políticas de desenvolvimento planejadas a curto e médio prazo, suas elites dirigentes e políticas adotam, como estratégias de desenvolvimento, ações de curto prazo, que viabilizam não só a valorização financeira dos mercados de capitais, como o gerenciamento das conhecidas e famigeradas taxas 
de juros, que se tornaram as grandes variáveis macroeconômicas da política econômica do governo.

Sendo assim, resta-nos levantar alguns elementos que poderiam fazer parte de agenda de desenvolvimento planejado, com vistas a atenuar os grandes desníveis socioeconômicos tanto em nível inter-regional como local da sociedade brasileira. Como parte dessa agenda, poderiam destacarse as seguintes políticas, ações e estratégias governamentais:

- formulação e implementação de políticas públicas e sociais emancipatórias, voltadas para a reinserção de grandes contigentes de excluídos no mercado de trabalho, com políticas de qualificação profissional e de emprego e renda de forma sistemática, em diversas regiões do país, principalmente, nos grandes centros populacionais mais atingidos pela violência urbana, pelo desemprego e pela marginalização social;

- implementação de política industrial voltada para o crescimento e aparecimento de novos atores econômicos nos diversos setores produtivos, apoiados pelo poder público e por políticas de desenvolvimento e de planejamento que objetivem, a médio e longo prazo, a retomada do crescimento, o fortalecimento e a abertura de empresas e postos de trabalho;

- retomada dos investimentos sociais em educação, saúde, saneamento básico, recuperando no setor público, por meio de investimentos e captação financeira, a capacidade produtiva de o Estado financiar e gerenciar serviços públicos de qualidade que atendam, em especial, os segmentos mais carentes da sociedade; e

- viabilidade de melhor articulação e coordenação entre as políticas econômica, fiscal e tributária, para criar alternativas ao crescimento econômico, fora do padrão de manutenção das altas taxas de juros, que só servem para estabilizar a economia. O país precisa criar alternativa ao fortíssimo ajuste fiscal, tributário e financeiro imposto pelas altas taxas de financiamento cobradas pelo governo para o fomento dos setores produtivos, como o agrícola e o industrial, e fomentar o setor de serviços.

Neste artigo, o propósito foi oferecer uma visão geral do planejamento governamental no Brasil, e entende-se que a compreensão do que foram o planejamento e o desenvolvimento econômico no país passa pela análise das políticas e ações priorizadas pelas elites brasileiras e capitaneadas pelo Estado. De resto, concordando com Maciel (1989), "o plano constitui não só o azimute que permite orientar a ação do Estado e da sociedade, mas a expressão democrática da vontade nacional” (p. 47). 
1 Esse plano era assim conhecido, porque o Ministro da Fazenda Horácio Láfer estava à frente de sua coordenação.

\section{Referências bibliográficas}

Alves, Denysard O.; SAYAD, João. O plano estratégico de desenvolvimento (1968-1970). In: LÁFER, Betty Mindlin. Planejamento no Brasil. São Paulo: Perspectiva, 1987.

Bielschowsky, Ricardo. Pensamento econômico brasileiro: o ciclo ideológico do desenvolvimentismo. Rio de Janeiro: IPEA/INPES, 1988.

Draibe, Sônia Miriam. Rumos e metamorfoses: Estado e industrialização no Brasil. São Paulo: Paz e Terra, 1985.

Gremaud, Amaury Patrick; Pires, Júlio Manuel. "Metas e bases" e I Plano Nacional de Desenvolvimento - I PND (1970-1974). In: Kon, Anita. Planejamento no Brasil II. São Paulo: Perspectiva, 1999.

IannI, Octávio. Estado e planejamento econômico no Brasil. Rio Janeiro: Civilização Brasileira, 1986.

Kon, Anita. Introdução: a experiência brasileira de planejamento público federal. In: KoN, Anita (Org.). Planejamento no Brasil II. São Paulo: Perspectiva, 1999.

LÁfer, Betty Mindlin. Planejamento no Brasil. São Paulo: Editora Perspectiva, 1987.

Macedo, Roberto B. M. Plano trienal de desenvolvimento econômico e social (19631965). In: Láfer, Betty Mindlin. Planejamento no Brasil. São Paulo: Perspectiva, 1987.

Maciel, Everardo. A crise do planejamento brasileiro. Revista do Serviço Público. Brasília: DF, v. 117 , no 1 , p. $37-48$, jun./set.1989.

Martins, Luciano. Estado capitalista e burocracia no Brasil pós-64. São Paulo: Paz e Terra, 1985.

Martone, Celso L. Análise do Plano de Ação Econômica do Governo (PAEG) (19641966). In: Láfer, Betty Mindlin. Planejamento no Brasil. São Paulo: Perspectiva, 1987.

SouzA, Nelson Mello e. O planejamento econômico no Brasil: considerações críticas. Revista de Administração Pública, Rio de Janeiro, v. 18, no 4, p. 25-71, out./dez. 1984. 
Revista do

Serviço

Público

Ano 55

Número 4

Out-Dez 2004

Antônio

Ricardo de

Souza é

doutorando em

Administração

pela Universi-

dade Federal da

Bahia.

Contato:

ricjanesalvador@ terra.com.br

Abstract

\section{As trajetórias do planejamento governamental no Brasil: meio século de experiências na administração pública}

Antônio Ricardo de Souza

Este artigo tem como objetivo analisar o papel do Estado na formulação do planejamento no Brasil a partir dos anos 30 , período que deu origem às primeiras iniciativas de planejamento, até os anos 80, momento em que se inicia a decadência do planejamento governamental no país. Optou-se por uma retrospectiva histórica que levantasse os principais aspectos inerentes ao planejamento como instrumento do desenvolvimento econômico deste período, verificando as principais mudanças ocorridas na sociedade. $\mathrm{O}$ artigo não pretende dar conta de todas as dimensões e complexidades do tema nem esgotar o assunto, que é polêmico e envolve muitas articulações teóricas com outras áreas, como administração pública, economia e ciência política. Desse modo, o artigo aponta na direção de que este balanço de análises das experiências de planejamento no Brasil demonstrou grandes avanços econômico-financeiros e alguns fracassos de coordenação e articulação com outras esferas, como a executiva e a financeira. Assim, desde os anos 80, em detrimento da crise do Estado, o planejamento entra em declínio nas agendas governamentais, impossibilitado, por questões de ordem financeira, de realizar suas funções de racionalização e eficiência econômica. Dessa forma, o Estado, nesse contexto, sempre representou, de forma geral, as diversas articulações de interesses capitaneados pelo planejamento como instrumento de intervenção e controle social no Brasil.

\section{La trayectoria del planeamiento gubernamental en Brasil: medio siglo de experiencias en la administración pública}

\section{Antônio Ricardo de Souza}

Este artículo tiene como objetivo analizar el rol del Estado en la formulación de la planificación en Brasil a partir de los años 30, período que dió origen a las primeras iniciativas de planificación, hasta los años 80 , momento en que se inicia la decandencia de la planificación gubernamental en el país. Se optó por una retropectiva histórica que levantase los principales aspectos inherentes a la planificación como instrumento de desarrollo económico de ese período, verificando las principales modificaciones ocurridas en la sociedad. El artículo no pretende abarcar todas las dimensiones y complejidades del tema, ni agotar el asunto que es polémico y envuelve articulaciones teóricas com otras áreas, como administración pública, economía y ciencia política. De ese modo, el artículo apunta en la dirección de que ese balance de análisis de las experiencias de planificación en Brasil demostró grandes avances económicos-financieros y algunos fracasos de coordinación y articulación com otras esferas, como por ejemplo, ejecutiva y financiera. Asi, desde los años 80, en detrimento de la crisis del Estado, a planificación entra en declinio en las agencias gubernamentales, imposibilitada por cuestiones de orden financiera para realizar sus funciones de racionalización e eficiencia económica.

De esa manera, el Estado en este contexto, siempre representó, de una forma general, las diversas articulaciones de intereses impulsados por la planificación como instrumento de intervención y control social en Brasil. 
The trajectories of the governmental planning in Brazil: half-century of experiences in the public administration

Antônio Ricardo de Souza

This paper is about to analyse the State's role on the formulation of planning in Brazil from the 30's - period of the first planning initiatives - to the 80's, when the government planning decays in the country. It was chosen a historical review that could raise the most important aspects regarding planning as an instrument for the economic development in this period, verifying the main changes which have occurred in the society. The article does not intend to cover all dimensions or complexities about the theme, nor to exhaust this controversial matter which has lots of theoretical articulations within other areas, such as economics and politic sciences. This way, this paper aims the direction in which this balance of analysis concerning planning experiences in Brazil have shown great economic and financial advances - and some coordination and other spheres articulation failure. Since the 80 's, to the detriment of the State crisis, planning starts declining in the governmental agendas not becoming possible for finantial reasons. The State, in this context, has always represented, in general, those various articulations of interference and social control in Brazil. 